\title{
Integrating Knowledge Management and Business Intelligence Processes for Empowering Government Business Organizations
}

\author{
Herison Surbakti \\ Information System Dept. Universitas Respati Yogyakarta \\ Yogyakarta - Indonesia
}

\begin{abstract}
Emergence of information technologies has transformed the way business marketing is done and how business enterprises are managing the resources and information. Trend of globalization has induced the fierce competitiveness among business enterprises within domestic and international markets. The major quest for the technologies is not limited to strategic value of an organization but also empower the organization work context by utilizing its resources. Knowledge management has emerged as the latest technomanagement trend for improving the work process and creating value for business organization operations. Knowledge management offers various techno-managerial implications to business organization for strategic development. However, there are scarce evidences on business intelligence, strategic management decision support related to business organization adopting these offerings. Major objective of Business Intelligence is to extract the information and find the hidden knowledge from all sources of data. Business Intelligence offers to make decision for enhancement of any organizations goal. The broad overview of research articulates an understanding of government based organizations about the adoption of Knowledge management based Business Intelligence solutions and its challenges. Data mining is playing a key role in Knowledge Management based systems for business organizations and its implication lies in the implementation of data mining algorithm for exploring the huge amount of data, which determines the pure knowledge.
\end{abstract}

Majority of the government organizational data remains in either unstructured form such as raw form of data (i.e. internal or external document) or with its employees in the form of experience. Knowledge management process deals with extraction of both tacit and explicit knowledge of organization for improving the performance of organization. However Business Intelligence (BI) on the other hand gained its importance with constant enhancement in technologies and tools for extracting the hidden knowledge and patterns. Hence it can be argued that both Business Intelligence and Knowledge Management are complimentary to each other for extracting and managing the knowledge. Thus it's very imperative for government organizations to have an integration of both Knowledge Management (KM) and Business Intelligence (BI) processes for enhancing the performance of the organization with respect to make organization decision for competitive environment and utilizing the organizational tacit knowledge.

The paper focuses on how BI and KM integration affect the government business organization while discussing its implementation challenges. The paper tries to analyze the correlation between Knowledge Management and Business Intelligence and exploring a road map for data mining based framework for Knowledge Management focusing government based organizations. Current situation of knowledge management strategic decision making and role of knowledge must need to be addressed before proposing any framework for government organization. Paper provides a detailed extensive literature review which aims to describe the basics of Knowledge Management based systems and integrating Business Intelligence with Knowledge Management. Study will draw a distinction between individual and organizational knowledge as well as whether knowledge is playing a key role in strategic development or not?

\section{Keywords}

Knowledge Management (KM), Business Intelligence (BI), Data Mining, Knowledge, Data Warehouse

\section{INTRODUCTION}

In the era of knowledge and technical innovation, it has been widely accepted that intangible assets of any business organization will be key to its success. Knowledge is supposed to be most important asset of any business organization, which has the largest influence on competitiveness, strategic development, and growth. Every organization has individual and organizational knowledge either in the form of raw data or information. Raw data or information retains within organization in the form of implicit knowledge and with limited resources. These information or raw data needs to be processed to acquire knowledge through the use of knowledge management \& data mining approach. Further knowledge can be made accessible to all through knowledge management process. Several environmental factors around which each business operates are: globalization, fierce competition, changes in organization structure, growth of information technology, and advent of knowledge management process [1]. Thus, emergence of Knowledge Management discipline has changed the direction of business strategic planning.

In the context of business organization, knowledge management is used to acquire the knowledge and experiences it for strategic development. Reuse of preciously acquired knowledge can be beneficial for preventing past failure and used as a guideline for fixing recurrent issues. It has been claimed that in business enterprise the knowledge not only embedded to document and repositories but also with enterprise routine, process, and practices [2].

Thus, knowledge is recognizing itself as one of the most important assets of any organization. Knowledge is acquired through the processing of available data of organization using data mining approaches. Data mining is a tool for processing the data to find out the relationship within the data that can be beneficial for the user. Data mining has the potential to use is as a powerful tool for the business intelligence but yet not fully recognized [3]. With the proliferation of the new technologies data mining has experienced an exponential 
growth and became an integral part of Knowledge Management system. Data mining algorithms are applied to explore the underlying data of business organization and after processing it determines the effectiveness of knowledge.

The major focus of this paper is role of Knowledge Management and Business Intelligence Processes for government based organization. Government based organizations means functional government agencies, various departments who perform public services. The paper aims to find how government organization managers adopt both KM and BI processes in public sector. Study aims to find out the interrelationship between Knowledge Management and Business Intelligence, and utilize it for strategic development and decision making.

In government based organization, there are extensive amount of data which is used within organization for business policy management, organization decision making, and growth \& development of organization. Since environment changes in any organization drastically, thus any change in the data also reflects the change in the system. The change can be related to various categories such as:

- Change in the quantity of data, it means with the growth in any organization amount of data will be increased substantially

- With the increased amount of data, the correlation between data also changes it means the relationship between application system also changed

Therefore these organization need to understand the data, process and mine the data to acquire knowledge from the large amount of data and extract intact and practical knowledge from random, vague, incomplete, and huge amount of data. This extracted knowledge can be utilized for decision making business intelligence. Primarily in the Knowledge management process, knowledge discovery process needs to apply data mining algorithms. Varieties of algorithms are available in data mining such as genetic algorithm, decision making, neural network, and fuzzy logic.

This paper is based on government based organizations, in which Knowledge Management process needs to implement for strategic development and decision making, and organizational development for the social and economical growth of the organization as well as improve its competitiveness in the era of globalization. Research aims to monitor, explore the evolution of business intelligence and Knowledge management implementation as a means to improve the work practice of business organization.

The fundamental purpose of the paper is to discuss the need of integrating $\mathrm{KM}$ and $\mathrm{BI}$ for exploiting structured \& unstructured raw data, implicit information of the organization and its challenges. This will helpful for creating an integrated knowledge based decision support system framework for government based organization which integrates both Business Intelligence and Knowledge management.

\section{LITERATURE REVIEW}

Most researchers and practitioners agreed on the practical implication of knowledge as one of the important assets of any organization. Knowledge Management and Business Intelligence are the two major areas of researchers concern. Knowledge management is a tool for empowering the knowledge within the organization [18], and useful for decision making. However, Business Intelligence has affected the business world the most for transforming the raw data into knowledge. This can be used for prediction analysis. A dearth research has been performed to explore Knowledge Management, Business Intelligence and its applicability within various application domains.

Authors have analyzed that Business intelligence is the broad categorization of applications of processing large amount of data for any organization to make prediction analysis [19], [20]. Operations such as OLAP (online analytical processing), data warehousing, data reporting, and business rule modeling are used by Business Intelligence. However, Knowledge Management is the process of knowledge acquiring and creation, knowledge sharing and dissemination and knowledge application. Authors have suggested that both Business Intelligence and Knowledge management are influenced by environment of the organization. The success ration of Knowledge Management is directly proportional to employee attitude [18], [21], [22]. Thus, there is a need of common platform for the organization where both employer and employee can share the knowledge.

In [23], author has proposed a scheme for transforming Knowledge Management into Business Intelligence. Author has also briefed certain parameters for implementing them to organization for a common workflow. However, the new or new solution cannot be added directly for the adoption purpose. Tacit knowledge plays a vital role in all the phases of any newly innovative process and implementation of tacit Knowledge Management and can be helpful for handling new problems.

Author has proposed a memory model for linking individual knowledge to knowledge managements. However, the practical implication of this model is very weak [23]. In [24], author has analyzed the outcome of knowledge management process over business intelligence and organizational performance with the help of influential variable. Therefore, it can be concluded that any knowledge management based system is a handy tool for achieving completive advantages. Some of the attempts have been done by the authors to integrate knowledge management for real time Business Intelligence and its benefits [25]. In [26], author has focused on tacit knowledge and explained it as a vital component for organization. However, management of tacit knowledge is a challenging task. Thus, there is the need of a common framework where tacit knowledge can be categorized into various degrees.

In [27], author has stated that both knowledge management and business intelligences are different from each other in terms of common foundation. Thus the interrelation between knowledge management and business intelligence needs to be explored. Simply an insight can be concluded that business intelligence is used for transforming data to knowledge, whereas Knowledge Management can be used as a tool for knowledge acquisition, knowledge sharing and to create new knowledge.

In [28], author has investigated the advantages and disadvantages of Knowledge Management, Business Intelligence and further proposed KMBI framework for the integration of Knowledge Management and Business Intelligence. This framework consist of three different layers namely data, presentation, and function integration.

With reference to various contexts, articles, paper reviewed, and application of Knowledge management it is analyzed that data mining is widely used toll for Knowledge Management and Business Intelligence both. Since both Knowledge 
Management and Business Intelligence are correlated and can be integrated for the better performance of an organization. Both are complimentary of each other, thus both can result in more effectiveness for government based business organization

\section{KNOWLEDGE MANAGEMENT}

\subsection{Knowledge}

Knowledge is defined as the mix frame of facts, expectation, skills, and combination of relevant information collected through experience, study, and reasoning, for enhancing the ability of decision making and evaluating the right context [4] [5]. However data, information and knowledge are the key terms which are the set member of knowledge management and may used interchangeably. Several arguments are made by the researchers about these terms, and defined as:

Data can refer to unprocessed, unstructured collections of random facts; Information refers to structured and processed data having some sense to the user, whereas Knowledge refers to the most refined and highly useful data for decision making and problem solving.

Various researchers have proposed several classification methods for classifying the knowledge. The classification of knowledge is helpful to the organizations for processing and managing their various available knowledge resources. Most widely accepted classification of knowledge is: Explicit and Tacit knowledge.

Explicit knowledge contains the knowledge, which has been already processed in the form of visual, text, diagrams, tables, manuals, and specific documents. Acquisition of explicit knowledge is easy, since it is in the form of table, manuals, and document; so as easy to manage too. In case of government based business organization explicit knowledge may contain such as business specification, product specification, contracts, and customer data [4] [6].

However, tacit knowledge refers to most valuable knowledge as it is in the form of experience, skills, and communications. It remains as understanding of people and expressed in the form of language [4] [6] [7]. Tacit knowledge is very beneficial to find best solutions and managing the organization on the basis of previously known knowledge. The only issue with tacit knowledge is, it cannot be articulated as it remains in the form of experience and skills. Since, tacit knowledge is personal, as it is retained in mind in the form of experience, skill and perceptions, hence very tough to manage, share and articulate it [7]. In case of government based organization tacit knowledge may include work such as process, project dealing, problem solving, and expert opinions.

Some authors have proposed that some part of the tacit knowledge can be acquired and converted into explicit knowledge. Several authors have proposed an hierarchy to have an understanding of data, information and knowledge types as shown in figure 1 [4] [6] [8].

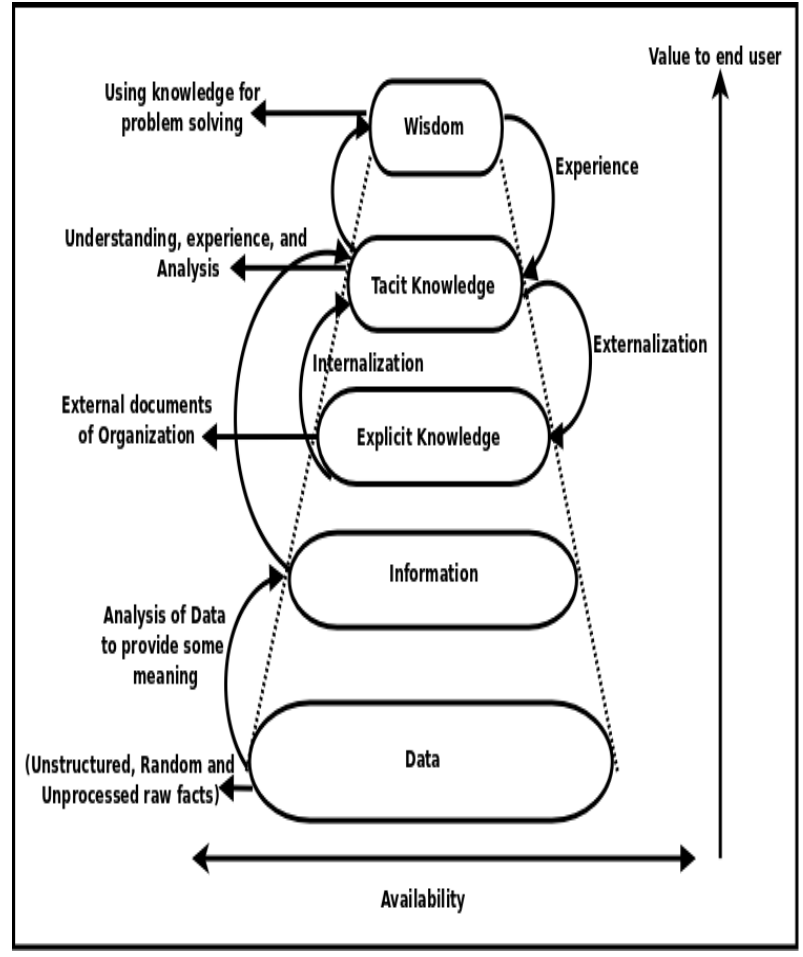

Figure 1: Relationship among Data, Information, Knowledge, and Wisdom

Except these, several attempts has been done by the authors for categorizing knowledge such as codified knowledge, common knowledge, social knowledge and embodied knowledge.

\subsection{Knowledge Management}

Knowledge management is an important part of any process management system and highly applicable to business organizations. It is an integral part for linking knowledge to business process management. Several authors have proposed various definitions for knowledge management. Knowledge management can be defined as the paradigm which is used for exploring knowledge resource, exploiting and sharing all knowledge (explicit, tacit) resource for enhancing the performance of any organization [9] [10]. Knowledge management provides framework and tools for knowledge acquisition, sharing, and creating knowledge for aiding end users for problem solving, and decision making.

Knowledge management system can be defined as the system for managing knowledge within organization for creating, acquiring, and sharing of knowledge. The basic idea of a knowledge management system is to provide newly created knowledge to the users for solving new problems and reusing of previous knowledge. Further researchers have provided different views on knowledge management system such as incorporating strategic decisions, processes and user component with knowledge management [9].

Knowledge management system has proved their success within organization. With the successful acquisition, creation, and sharing of knowledge; organizations are improving the performance, organizations learning for gaining competitive advantage. On the basis of previous available research on knowledge management system over business organization, the benefit can be summarized as in figure 2 [4] [10]. 


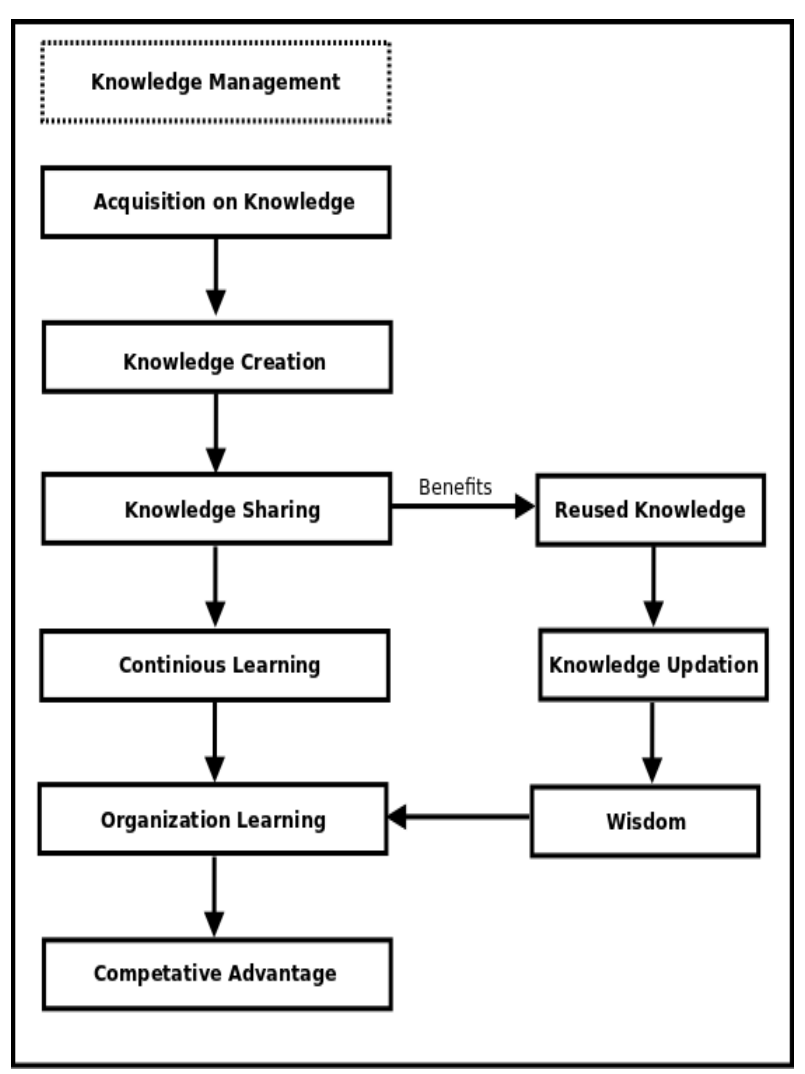

Figure 2: Overview of KMS (Knowledge Management System)

Researchers and practitioners have discussed challenges and barriers that may cause the performance degradation using knowledge management system. Hence, there is a need of more planned, structured and coherent approach for utilizing knowledge in more efficient way so that it can prove more beneficial for government organizations.

\subsection{Knowledge Management Models}

Limited processes, procedures and structured approach lead the development of more structured approach for managing knowledge resources within organization. To overcome these challenges knowledge management modeling is used for creating and managing the knowledge. Models provide an easy presentation of a real system using its main features. Modeling is helpful for providing structured methods for understanding, implementing and evaluating knowledge management system. However, researchers argued over the advantage and disadvantage of these models while implementing for the organization.

\subsubsection{Generic Knowledge Management Models}

Many generic models, methods have been developed by the researchers for enhancing knowledge management. Some of the well known models are SECI Model [10], knowledge map [11], Ontology based knowledge management [12], Activity based knowledge management [13], and knowledge management models [14].

\subsubsection{SECI Model}

SECI model is used for creating knowledge using four different modes known as Socialization, Internalization, Combination and Externalization as represented in figure 3 [10] .

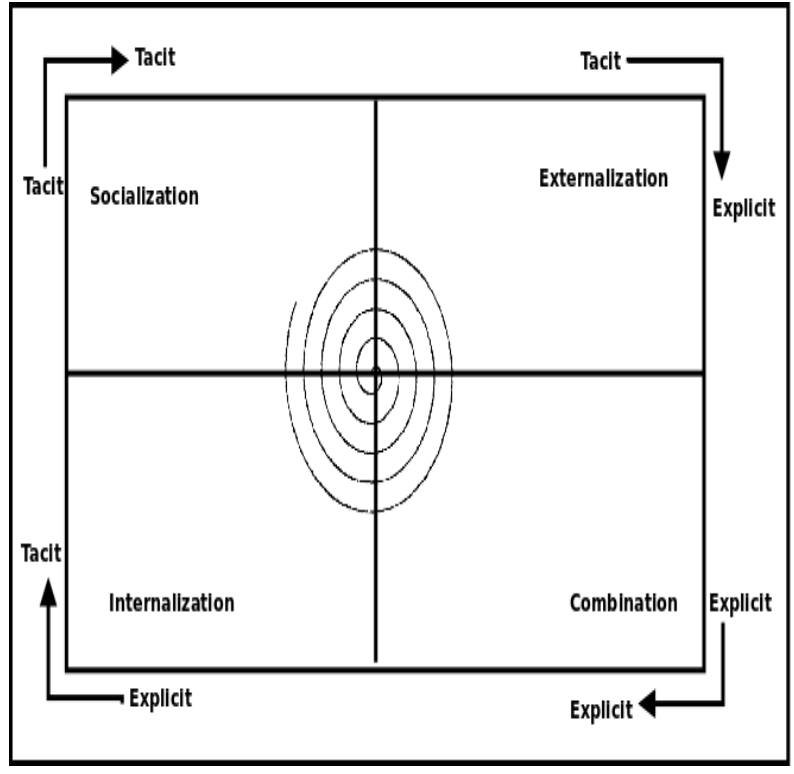

Figure 3: SECI Model

Author has proposed knowledge creation can be a nonstop process, to recreate company in it by creating new knowledge. Creation of a new knowledge is a specialized activity where each user in an organization act as a knowledge worker and it begins with each individual.

Socialization is the process for acquiring and sharing experiences or tacit knowledge through observation and conversations. Externalization is used for transforming tacit knowledge into explicit knowledge. Combination process is used for combing various available explicit knowledge sources for creating new knowledge. Internalization is the process for developing skills, experiences by continuous learning and by applying existing explicit knowledge to form tacit knowledge.

\subsubsection{Activity based Knowledge Management Model}

Activity based model is proposed especially for activities of construction projects [13]. Author has proposed that information and knowledge from all sources are classified and stored as activity unit, hence named activity based modeling. Major aim of this model is reusing the knowledge and easy knowledge acquisition. Integrated definition function (IDF) modeling method is used for defining the model of knowledge management. Activity based knowledge divides the process into top-level and sub-level phase. Top-level phases are such as knowledge acquisition; knowledge extraction, knowledge storage, knowledge sharing, and knowledge update [13]. However sub-level phases consists the division of top-level phases into small tasks.

\subsubsection{Knowledge Map}

Using activity based knowledge management model as the base mode. This model is used for acquiring and re-presenting the knowledge known as knowledge map [11]. Knowledge map is the schematic graphical representation which tells what knowledge resource is available and missing in knowledge management. It's an easy way for user to find the required knowledge. This model uses previous knowledge map of similar activity to form new one. Authors have proposed knowledge management architecture for describing components of knowledge management. This architecture consists of four different layers as Interface layer, Access 
layer, Application layer, and database layer [11] [13] as shown in figure 4 .

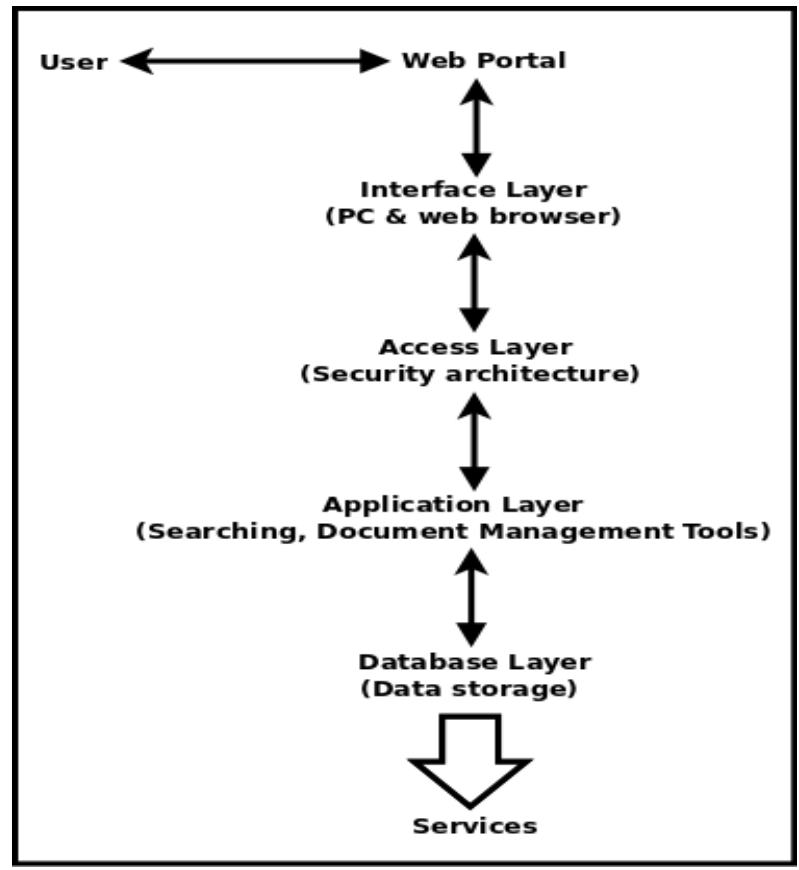

Figure 4: Knowledge Management Model

\subsubsection{Tacit-Explicit Knowledge Continuum}

A model has been proposed for transforming tacit knowledge into explicit knowledge in organization; there should be clear understanding about dynamic nature of knowledge [15]. Author has also argued that knowledge can also be harmful for organizations, if it is invalid, misleading, discouraging, and unsatisfactory for organization. Knowledge is dynamic in nature as it changes with time. Author has suggested in place of extract knowledge from users, it should be more productive like creating a knowledge culture for sharing knowledge through face to face communication.

However various other knowledge management models such as IMPaKT, e-COGNOS are proposed by authors depending on different organizations. Reviewing the literature and analysis helps in identifying the characteristics, their relationships, and components for knowledge management modeling related to government based organizations.

\section{BUSINESS INTELLIGENCE}

\subsection{Business Intelligence}

Knowledge management plays vital role in strategic decision making within organization. On the other hand Business Intelligence has gained significant importance in business world due to wide range of technologic advancement. Business Intelligence offers wide range of solutions such as advertising business, improving economy, and customer support. Business Intelligence can be defined as the combination of data analytical tools for gathering and effective use of organization information to improve business management. Some authors have argued business intelligence as online decision making process. Authors have suggested that Business Intelligence as a set of components such as data warehouse, data mining, OLAP, and decision support system [16] [17]. Figure 5 depicts the input and processing of Business Intelligence process.

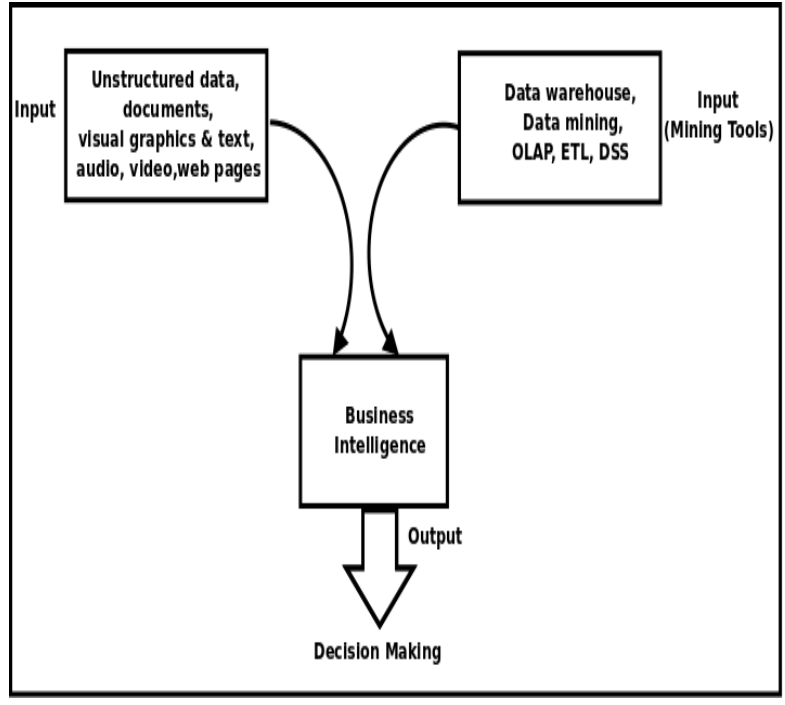

Figure 5: Inputs and Outputs of Business Intelligence

Basic description of Business Intelligence components are described in next subsection.

\subsubsection{Data Warehouse}

Data warehouse is a system used for data repository and data analysis. Data warehouse stores the data into repositories, where it is processed and organized for strategic decisions. Information in the warehouse is stored in the form of Meta data. Metadata helps the user to understand what and where the data is available, and how to access it and when to use the data. Data warehouse system are categorized such as data mart, OLAP (Online analytical processing), and OLTP (Online transaction processing).

\subsubsection{Data Mart}

Data marts are the simpler form of data warehouse which is especially focused for single task such as for any individual departments. Data mart uses the data either from internal operations or from external data source.

\subsubsection{OLAP (Online Analytical Processing)}

OLAP is a multidimensional model which support roll-up, and drill operations. OLAP are low volume transactions, but consists of complex queries. OLAP applications are widely accepted by data mining techniques.

\subsubsection{Data Mining}

Data mining is the process of mining the available data to discover the hidden patterns, trends, and correlation among the data. Huge amount of data is stored into data warehouse and processed using data mining tools and techniques.

\subsubsection{ETL (Extraction, Transfer, and Load)}

ETL process is the group of three different processes for extracting and loading into database. Extraction process refers to data extraction from various sources including internal and external sources. Transfer process refers to data cleaning for correlating the inconsistent, missing, and invalid data sets. Finally load refers to load the cleaned data into data warehouse.

\section{INTEGRATION OF BUSINESS INTELLIGENCE AND KNOWLEDGE MANAGEMENT}

Business Intelligence and Knowledge Management both have shown significant improvement for organizational 
performance. However, both Business Intelligence and Knowledge Management are different but used for knowledge discovery and decision making. There are various arguments by researcher for discussing whether Business Intelligence is part of Knowledge Management or Knowledge Management is part of Business Intelligence. Simply Knowledge management deals with both tacit and explicit knowledge, whereas Business Intelligence deals with only explicit knowledge [22]. In [28] [29], authors have proposed that integration of Knowledge management and Business Intelligence will broaden the research area of knowledge, while improving the intelligence. Business Intelligence process converts data into information then into knowledge which finally used for meeting user requirements. However, major emphasis of Knowledge management is on knowledge and improves the utilization process. In [27], author has proposed an architecture which is an extension of business intelligence model. In [16], author has argued that no knowledge framework which can support analytical knowledge generated by business intelligence. Author has proposed a research direction and framework for intelligent Knowledge management. In [30], author has proposed architecture for integrating Business intelligence and knowledge management with three different layers as interface, data level integration, and system level integration.

The authors have proposed their views on integration of Business intelligence and knowledge management for achieving more intelligence [27] [29].

The major benefits of integrated framework are:

- It ensures to provide highest quality of services to individual users in the global market.

- Tacit knowledge (user experiences, user skills, understanding) can be useful for business intelligence.

- It provides both understanding of business context, context interpretation for user benefits.

\section{BASIC FRAMEWORK FOR KM \& BI INTEGRATION IN GOVERNMENT ORGANIZATIONS}

Management of knowledge is of much importance for government for dealing with the challenges of knowledge economy. Government organizations facing many challenges such as: administrative, executive, and fierce competitiveness for achieving organizational goal. Today government organizations need knowledge work and knowledge workers for creating \& sharing the knowledge to enhance interpersonal and organizational skills. Knowledge management and business intelligence has the potential to strengthen the effectiveness and competitiveness of government sectors. Thus there is a need of having a combined integrated framework of Business Intelligence and Knowledge management for achieving this goal.

Several researchers has proposed a variety of models, integrated framework, and perspectives explained in literature review section in detail. Most important factors or elements while defining the framework for the government organization are: users (organizational and general user), processes, and technology.
On the basis of available literature review, knowledge management model; initial scope of the integrated framework has been proposed for the government organizations. The initial scope represents the possible outcomes and features which are expected from the BI, KM integrated framework. Figure 6 represents the possible features that are expected from the integrated framework. On the basis of expected outcomes of integrated framework, it can consist of several layers.

Government organizations have both external and internal data. Internal data contains data of organization either structured or unstructured, whereas external data contains user data. Except it experience, skill, and understanding of organization people can also taken into account. The integrated framework needs to handle both explicit and tacit knowledge. Thus, a layer can be used of handling the knowledge source. Further unstructured and structured data needs to be stored for further processing. After processing the unstructured and structured data knowledge can be extracted as KDD (Knowledge Discovery in Database) or BI processes. Finally extracted knowledge can be visualized and integrated with decision support system.

On analyzing the expected outcomes from framework it can be argued that there can be possible interaction between Knowledge Management processes and Business Intelligence Processes. The major aspect of the integrated framework is inclusion of both explicit and tacit knowledge which benefits organizational decision goals as well as work skills of employee using tacit knowledge. Extractions of tacit knowledge and its utilization is really a challenging task for any organization and have many positive influences.

\section{CONCLUSION \& FUTURE WORK}

Potentially this research would assist in the development of a integrated model for Business Intelligence and Knowledge Management which helps government based organization for strategic development. This will be helpful for evaluating their existing knowledge management system. It can work as guidance to the organization to utilize their knowledge base at both individual and organizational level. Business Intelligence can be useful for Knowledge Management in a collaborated form. This expended integration will improve the effectiveness of knowledge at individual and organizational level.

Implementation of integrated $\mathrm{KM}$ and $\mathrm{BI}$ framework for government organization can improve quality and efficiency of public services. In general it can be argued that government sectors are mostly lagging behind the private sectors. Hence in this fierce competition in the era of globalization government organization needs to adopt these Knowledge Management and Business Intelligence processes to empower themselves.

In this paper a base framework with its possible expected outcomes and detailed literature survey has been proposed. Further research aims to develop new knowledge management framework integration with business intelligence that enables the strategic development, decision making, and resources utilization with in government organization. This model will be helpful for categorizing the knowledge and use of knowledge for predictive analysis. This proposed model will be evaluated and validated with current integration models of knowledge management and business intelligence. 


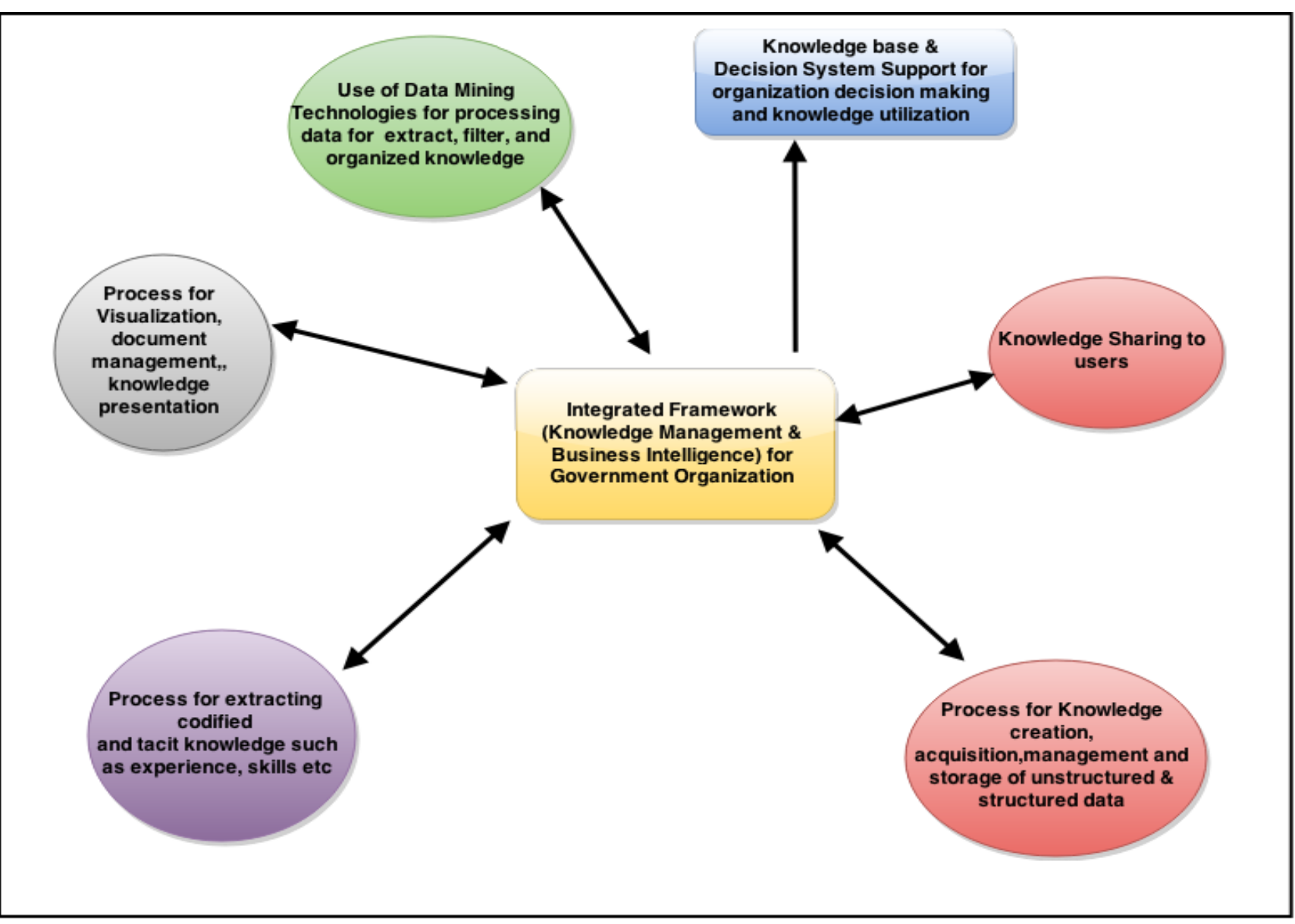

Figure 6: Basic integrated framework for BI and KM in Government Organizations

\section{REFERENCES}

[1] Handzic, Meliha. "Knowledge management in SMEs." CACCI Journal 1 (2006): 1-11.

[2] Wenger, Etienne, Richard Arnold McDermott, and William Snyder. Cultivating communities of practice: A guide to managing knowledge. Harvard Business Press, 2002.

[3] Wang, John, Xiaohua Hu, and Dan Zhu. "Diminishing downsides of data mining." International Journal of Business Intelligence and Data Mining 2.2 (2007): 177196.

[4] Awad, E. M., \& Ghaziri, H. M. Knowledge Management, 2004.ed: Prentice-Hall, Upper Saddle River, New Jersey.

[5] Bennet, D., \& Bennet, A. (2008). Engaging tacit knowledge in support of organizational learning. Vine, 38(1), 72-94.

[6] Bierly III, P. E., Kessler, E. H., \& Christensen, E. W. (2000). Organizational learning, knowledge and wisdom. Journal of organizational change management, 13(6), 595-618.

[7] Alonderiene, R. a. (2006). Tacit knowledge acquisition and transfer in the process of informal learning. Problems and perspectives in management, 4 (3), 134145

[8] Bellinger, G., Castro, D., \& Mills, A. (2004). Data, information, knowledge, and wisdom.
[9] Jennex, M. E. (2005). Case Studies in Knowledge Management IGI Global.

[10] Nonaka, I. a. (2005). The knowledge-creating company: How Japanese companies create the dynamics of innovation. Oxford university press.

[11] Egbu, C. O. (2005). Knowledge management for sustainable competitiveness in small and medium surveying practices. Structural Survey, 23 (1), 7-21.

[12] Gruber, T. R. (1993). A translation approach to portable ontology specifications Knowledge acquisition, 5 (2), 199-220

[13] Hernandez-Matias, J. a.-G. (2008). an integrated modelling framework to support manufacturing system diagnosis for continuous improvement. Robotics and computer-integrated manufacturing, 24 (2), 187-199.

[14] Abdullah, M. S. (2002). Knowledge modelling techniques for developing knowledge management systems. Third European Conference on Knowledge Management: Trinity College Dublin, Ireland, 24-25 September 2002, (p. 17).

[15] McInerney, C. (2002). Knowledge management and the dynamic nature of knowledge. Journal of the American Society for Information Science and Technology, 53(12), 1009-1018.

[16] Langseth, J., \& Vivatrat, N. (2003). Why Proactive Business Intelligence is a Hallmark of the Real-Time 
Enterprise: Outward Bound. Intelligent Enterprise,5(18), 34-41.

[17] Curko, K., Vuksic, V. B., \& Loncar, A. (2009). The Role of Business Process Management Systems and Business Intelligence Systems in Knowledge Management. International Journal of Computers And Communications, 3(2), 17-24.

[18] Wilson, T. D. (2002). The nonsense of knowledge management. Information research, 8(1), 8-1.

[19] Williams, S., \& Williams, N. (2010). The profit impact of business intelligence. Morgan Kaufmann.

[20] Cook, C., \& Cook, M. (2000). The Convergence of Knowledge Management and Business Intelligence.

[21] Paiva, E. L., \& Gonçalo, C. R. (2008). Organisational knowledge and industry dynamism: an empirical analysis. International Journal of Innovation and Learning, 5(1), 66-80.

[22] Herschel, R. T., \& Jones, N. E. (2005). Knowledge management and business intelligence: the importance of integration. Journal of Knowledge Management,9(4), 4555.

[23] Meyer, B., \& Sugiyama, K. (2007). The concept of knowledge in KM: a dimensional model. Journal of knowledge management, 11(1), 17-35.

[24] Campbell, H. M. (2010, April). The liberation of Intellectual Capital through the natural evolution of
Knowledge Management Systems. In Information Management and Engineering (ICIME), 2010 The 2nd IEEE International Conference on (pp. 218-225). IEEE.

[25] You, H. (2010, May). A Knowledge Management Approach for Real-time Business Intelligence. In Intelligent Systems and Applications (ISA), 2010 2nd International Workshop on (pp. 1-4). IEEE.

[26] Holsapple, C., Lee-Post, A., \& Pakath, R. (2014). A unified foundation for business analytics. Decision Support Systems, 64, 130-141.

[27] Weidong, Z., Weihui, D., \& Kunlong, Y. (2010, April). The relationship of business intelligence and knowledge management. In Information Management and Engineering (ICIME), 2010 The 2nd IEEE International Conference on (pp. 26-29). IEEE.

[28] Cheng, L., \& Cheng, P. (2011, October). Integration: Knowledge Management and Business Intelligence. In Business Intelligence and Financial Engineering (BIFE), 2011 Fourth International Conference on (pp. 307-310). IEEE.

[29] Negash, S. (2004). Business intelligence. The Communications of the Association for Information Systems, 13(1), 54.

[30] Baars, H., \& Kemper, H. G. (2008). Management support with structured and unstructured data-an integrated business intelligence framework. Information Systems Management, 25(2), 132-148. 